\section{P148 "FAST-TRACK" STD SERVICES IN AN URBAN STD CLINIC: INCREASED CLINICAL CAPACITY, BUT REDUCED OPPORTUNITIES FOR SAME-DAY TREATMENT}

doi:10.1136/sextrans-2012-050601c.148

${ }^{1} \mathrm{~B}$ Stoner, ${ }^{*}{ }^{1} \mathrm{H}$ Reno, ${ }^{2} \mathrm{C}$ Brethauer, ${ }^{2} \mathrm{D}$ Spear, ${ }^{2} \mathrm{R}$ Knaup. ${ }^{1}$ Washington University, St. Louis, Missouri, USA; ${ }^{2}$ St. Louis County Department of Health, St. Louis, Missouri, USA

Background Public health sexually transmitted disease (STD) clinics in the US continue to face service cutbacks due to financial pressures. "Fast-track" services (urine-based screening without a physical examination) allow for greater patient throughput, but may impede provision of same-day STD treatment.

Objectives (1) to demonstrate the extent to which fast-track implementation leads to increased service capacity; and (2) to document the percentage of fast-track cases with STD requiring further treatment.

Methods Demographic, behavioural, and clinical data analysis from fast-track service delivery in St. Louis County STD Clinic (urban St. Louis, Missouri, USA) from January 2009 to August 2011.

Results Implementation of fast-track services resulted in an increase in clinic throughput of 34.8 patients per month, and a decrease in patients turned away without care $(5.6 \%)$. Most fast-track patients were male $(65.9 \%)$, reflecting general clinic demographic trends. Infection rates among fast-track patients were $9.6 \%$ for Chlamydia trachomatis and $0.7 \%$ for Neisseria gonorrhoeae; these patients were contacted by telephone and instructed to return to clinic for treatment. Effective treatment was documented for $67.0 \%$ of infected patients.

Conclusion Implementation of fast-track services resulted in increased clinic capacity. However, substantial staff time and effort were required to ensure adequate treatment for those testing positive for STD. Enhanced risk assessment prior to fast-track screening may help identify those patients who will benefit from full STD clinical examination and same-day treatment.

\section{P149 EVOLUTION OF THE NCSP: INTEGRATING CHLAMYDIA SCREENING INTO COMMUNITY HEALTH SERVICES; POLICY AND PRACTICE DEVELOPMENTS IN ENGLAND}

doi:10.1136/sextrans-2012-050601c.149

${ }^{1} \mathrm{~J}$ Clarke, ${ }^{2} \mathrm{~A}$ Bone. ${ }^{* 1}$ NCSAG; ${ }^{2}$ NCSP, Health Protection Agency, London, UK

Background The National Chlamydia Screening Programme is a major component of sexual health provision in England. Over 1.4 million tests were performed on asymptomatic under 25-year olds in 2010/2011, and over 87000 diagnoses made. The expansion of chlamydia testing services in the NHS has occurred predominantly outside of GUM utilising both traditional health services and introducing alternative approaches for young people to access testing. Coverage of screening has been higher in deprived areas and among young people at increased risk of infection.

Discussion The NCSP is evolving from a stand-alone programme to one that is integrated in primary care and sexual health services, with outreach screening being restricted to hard to reach groups. This integration is occurring both in terms of the way chlamydia screening is commissioned and provided, and in terms of data collection, removing the requirement for chlamydia-specific services. This process is expected to substantially improve value for money and maximise synergies between chlamydia prevention and other services. Clinical research and modelling, comparison with other programmes around the world and the major organisational changes in the NHS and public health system continue to shape the commissioning and delivery of screening. Clinical practice, from distribution of test kits to partner notification and treatment, is increasingly dependent upon electronic resources. Key discussion points include: How can we continue to develop flexible, responsive community sexual health services that include chlamydia screening as a core component? Will evaluation criteria for quality assurance and for clinical effectiveness currently applied to a stand-alone NCSP be valid in the integrated models?

\section{P150 FEMALES UNDER 16 ATTENDING GUM}

doi:10.1136/sextrans-2012-050601c.150

${ }^{1} \mathrm{M}$ King, ${ }^{*}{ }^{2} \mathrm{C}$ J F Priestley. ${ }^{1}$ Dorset County Hospital Foundation Trust, Dorset, UK; ${ }^{2}$ Dorset County Hospital, Dorset, UK

Background The government set out a number of sexual health targets in the white paper "Choosing Health" 2004 and include. A reduction in the under 18 conception rate, An increase in the percentage of people aged 15-24 accepting chlamydia screening. Young people need to be able to easily access sexual health services in order to prevent, diagnose and treat sexually transmitted infections (STIs) and gain advice and contraception to protect against unintended pregnancy. A significant proportion of patients under the age of 16 are seen, who may have child protection concerns or be vulnerable. We wanted to examine the reasons for their attendance.

Aims In female patients under the age of 16 attending the integrated sexual health clinic, to identify. The reasons for attendance. STI diagnosis and treatment. Contraceptive use and provision. The degree of sexual risk-taking in under 16s, including sexual history, condom use, requests for post coital contraception and pregnancy testing, and the number of pregnancies. Other child protection concerns, including age at first intercourse and age of sexual partner, and parental awareness of their sexual activity. Other factors that contribute to vulnerability and risk-taking in, including alcohol and drug use, mental health issues, low self esteem, homelessness and chaotic life style.

Methodology Service provision was reviewed in comparison to the DoH standards. 50 sets of records were analysed.

Results Reasons for attendance Contraception 80\% PCC $60 \%$ Pregnancy Test 20\% Sexual Screening 42\% Recommendation: (1) development of integrated sexual health clinics, (2) PCT commissions a local, accessible abortion service, (3) develop links with other drug alcohol services, (4) combine sexual history sheet with the under 16s proforma, (5) Improve education about LARC in schools to promote uptake, (6) encourage a self-taken chlamydia swab or urine sample in those who decline full STI screening.

\section{P151 HOW EFFECTIVE IS TARGETED OUTREACH?}

doi:10.1136/sextrans-2012-050601c.151

V Sellors, ${ }^{*}$ A Akers, E Bostock, R Dutton, A Apoola. Derby Hospitals NHS Foundation trust, Derby, UK

Background The national sexual health strategy recommends that services should meet the needs of local communities and identifies where service developments are needed most. The financial pressures of the health service and the operational pressures of trying to meet a 48-h target make it difficult to establish targeted outreach projects to reduce the burden of STIs and the uptake of STI/HIV screening and testing in hard to reach groups.

Methods A needs assessment was carried out with relevant partner organisations and an outreach project with sexual health advisors 